\title{
ESTUDOS PRELIMINARES DA ATIVIDADE ANTIMICROBIANA DE PROPOLIS
}

\author{
Eduardo Vicentea \\ Elisa Yoko Hirookab
}

\begin{abstract}
RESUMO
A atividade antimicrobiana de própolis foi estudada em Streptococcus pyogenes, microbiota de cavidade oral e fungos produtores de micotoxinas. Os meios CAM e BDA foram utilizados para o cultivo de fungos e o ágar Rogosa, APT, BHI e sangue para bactérias orais, empregando-se a combinação das técnicas de semeadura em profundidade e placa gradiente de Szibalsky. Os fungos toxigênicos não foram inibidos pela própolis. A própolis apresentou efeito bacteriostático em microrganismos da cavidade oral semeados em profundidade na placa gradiente, observando-se crescimento inclusive com $1,0 \%$ de própolis após 72 horas. Em S. pyogenes, apenas a produção de hemolisina foi inibida em ágar sangue, porém observou-se efeito bactericida em caldo BHI + própolis. A atividade de própolis em $S$. pyogenes dependeu da aeração e tipo de nutrientes e provavelmente além de açāo antimicrobiana, as propriedades farmaco-dinâmicas determinam o efeito final do sistema biológico.
\end{abstract}

PALAVRAS-CHAVE:Própolis; Streptococcus pyogenes; Bactericida; Bacteriostático.

\section{1 - INTRODUÇ $\tilde{A} O$}

Própolis é uma substância resinosa produzida peląs abeThas (Apis mellifera L.) e utilizada na medicina popular devido a propriedade farmaco-dinảmica e antimicrobiana (AZEVEDO \& FLECHTMANN, 1983; TREVISAN, 1983; MERESTA \& MERESTA, 1985). Esta substāncia c composta de $55 \%$ de resinas e bálsamos, $30 \%$ de ceras, $10 \%$ de óleos voláteis c $5 \%$ de pólen, sendo identificados ácidos aromáti$\cos$ insaturados e flavonóides entre substāncias com atividade biologica (IORICH, 1981, apud TREVISAN, 1983), mostra microelementos (DIMITROV-MANGADIEV, 1976) e apesar da constataçẫo de atividade enzimática de interesse, estas estão entre componentes pouco estudados (POPESCU et alii, 1976).

A atävidade báctericida de própolis foi descrita por KIVALKINA em 1959 (apud AZEVEDO \& FLECHTMANN, 1963), que posteriormente também observou efeito bacteriostático de amplo espectro, cuja intensidade variou de acordo com a procedencia (KIVALKINA, 1976). Entre outras propriedades estão a efeito cicatrizante, ancstésico e anti-inflamatório (DONADIEU, 1980, apud TREVISAN, 1983), porém constatou-se atividade mitogênica depressiva em meristemas de Allium cepa (POPOVICI, 1976) e manifestações cutâneas alérgicas em apicultores (TREVISAN, 1983).

Tendo em vista que a própolis tem sido utilizada em escala comercial na homcopatia, o presente trabalho propōe estudar atividade antimicrobiana desta substância em microrganismos da cavidade oral, dando maior ênfase a Streptococcus pyogenes, assim como avaliar a viabilidade da utilização deste composto na preservaçăo de alimentos com baixa umidade, visando a inibição de fungos toxigênicos.

\section{2 - MATERIAL E MÉTODOS}

Soluçâo de própolis "in natura"

A soluçāo de própolis a 10,0\% foi preparada com amostra proveniente de Rio Claro-SP em etanol absoluto, obtendo-se um líqui do límpido de coloração amarclada após a fil. tração do macerado a $\cdot 20^{\circ} \mathrm{C}$ para eliminação de ceras. A so. lução aquosa a $20,0 \%$ foi obtida adicionando-se $10,0 \mathrm{~mL}$ de $\mathrm{H}_{2} \mathrm{O}$ a $20,0 \mathrm{ml}$ de solução alcoólica a $10,0 \%$ e a mistura mantida a $50^{\circ} \mathrm{C}$ em banho de água, até a redução para volu. me final de $10,0 \mathrm{ml}$, considerando a termoestabilidade de própolis e eliminaçấo do ctanol por evaporação (PRADO FILHO et alii, 1962).

Teste de solubilidade de própolis

A solubilidade de própolis foi analisada em $\mathrm{H}_{2} \mathrm{O}, \mathrm{HCL}$ $1,0 \mathrm{~N}, \mathrm{NaOH} 1,0 \mathrm{~N}$, etanol, etanol $+\mathrm{H}_{2} \mathrm{O}(1: 2)$, Tween 20 e 80 , n-hexano e clorofórmio.

Efeito de própolis em fungos toxigênicos

Solução aquosa de esporos em $0,1 \%$ de Tween 80 foi preparada com Aspergillus parasitictus NRRL 2999

Recebido em 09/11/87

a Estagiário da disciplina de Microbiologia, Departamento de Patologia Geral - CCB/UEL

b Departamento de Patologia Geral - CCB/UEL 
NRRL $5520\left(\mathrm{AFB}_{1}\right.$ e $\left.\mathrm{B}_{2}\right)$, A. flavus NRRL $325 I\left(A F B_{1}\right.$ e $\mathrm{B}_{2}$ ), A. ochraceus NRRL 3174 (ocratoxina A e 4hidroximeteína), A. melleus NRRL 3519 (ocratoxina A), Penicillium roquefort HPB 110376.8 (Patulina) e Penicillium citrinum AVA 533 (citrinina).

A seguir a suspensão foi semeada em estrias em ágar batata dextrosado (BDA) contendo 0,1 a $1,0 \%$ de própolis, segundo a técnica de placa gradiente de Szibalski (BRAUDE, 1980).

A atividade de própolis "in natura" foi avaliada em ágar (BDA) e ágar coco (CAM), semeando-se esporos no centro e colocando-se fragmentos de propolis ou $0,1 \mathrm{ml}$ de solução alcoólica a $10,0 \%$, respectivamente, em lados opostos da placa. As placas foram incubadas a $25^{\circ} \mathrm{C}$ c observadas durante 6 dias.

\section{Efeito de própolis em microbiota da cavidade oral}

A placa gradiente foi preparada com ágar "all purpose medium with tween" (APT) e Rogosa contendo 0,1 a $1,0 \%$ de própolis em solução alcoólica e $1,0 \mathrm{ml}$ de etanol como controle. $\mathrm{O}$ inóculo consistiu de $0,1 \mathrm{ml}$ de saliva em $50,0 \mathrm{ml}$ dos respectivos meios de cultura mantidos a $50^{\circ} \mathrm{C}$ e plaqueados sobre a base inclinada contendo própolis. As placas foram incubadas a $37^{\circ} \mathrm{C}$ e observadas durante 4 dias.

Efeito de própolis em estreptococos $\alpha$ e $\beta$ hemolíticos - crescimento em agar sangue

A atividade antimicrobiana de própolis foi testada pela técnica de BAUER et alii (1966), umedecendo os discos de papel de filtro com 5,0 גl de soluçăo alcóblica de própolis a $10,0 \%$ e secos a $37^{\circ} \mathrm{C}$

A inibição de atividade hemolítica em $S$. pyogenes foi testada cobrindo-se metade da superfície de ágar sangue com $0,1 \mathrm{ml}$ de solução aquosa de própolis a $20,0 \%$ e semeadas em estrias com a cultura de estreptococos.

\section{- crescimento em meio líquido}

Quatro séries de 6 tubos $18 \times 180 \mathrm{~mm}$ contendo 40,0 $\mathrm{ml}$ de caldo $\mathrm{BHI}$, caldo base para ágar sangue (CB) adicionado de $0,4 \%$ e $0,7 \%$ de $\mathrm{NaCl}$ foram preparadas e 3 tubos de cada série, adicionados de $8,0 \%$ de sangue desfibrinado de carneiro. Duas séries foram adicionada de $30 \mu l$ de solução aquosa de própolis a $20,0 \%$ e incubadas a $37^{\circ} \mathrm{C}$ por 20 horas em cultura mantida sem agitação ou sob agitação a $70 \mathrm{rpm}$ em banho de água da Etica, com os respectivos controles sem própolis. A confirmaçāo do crescimento foi realizade semeando-se todos os tubos em ágar sangue.

$\mathrm{O}$ esquema da experiência está apresentado na figura 1 .

\section{3 - RESULTADOS}

A própolis "in natura" solubilizou-se facilmente em etanol, clorofórmio e $\mathrm{NaOH} 1,0 \mathrm{~N}$, porém insolúvel em $\mathrm{H}_{2} \mathrm{O}$ e $\mathrm{HCl} 1,0 \mathrm{~N}$.

O extrato alcoólico de própolis em concentração de 0,1 a $1,0 \%$ não inibiu nenhuma das linhagens de fungos micotoxigênicos testados (tabela 1 ).

Tabela 1 - Teste da Atividade Antimicrobiana de Própolis em Fungos Toxigênicos

\begin{tabular}{cccc}
\hline $\begin{array}{c}\text { Concentração } \\
\text { de Própolis }\end{array}$ & $3 \%$ dia & 49 dia & 59 dia \\
\cline { 2 - 4 } $1.0 \%$ & + & ++ & +++ \\
$0.5 \%$ & + & ++ & +++ \\
$0.2 \%$ & + & ++ & +++ \\
$0.1 \%$ & + & ++ & +++ \\
\hline
\end{tabular}

* Incubação a $25^{\circ} \mathrm{C}$

** g/\% de própolis

Variação do Número de Colônias: de - até +++

Quanto a microbiota da cavidade oral, apresentada na tabela 2 , as concentraçōes de própolis em placa gradiente inibiu gradativamente o crescimento microbiano semeado pela técnica de pourplate, e o ágar APT permitiu o desenvolvimento de maior número de colonias. A concentração de 0,5 e 1,0\% de própolis inibiu o crescimento da microbiota oral apenas até o 20 dia, cessando o seu efeito inibitório após 72 horas nas concentraçóes baixas. A adição de etanol em placa controle sem própolis não interferiu no crescimento de microrganismos da cavidade oral.

Tahela 2 - Anslise da Atividade Antinsctobiana de Própolis em microbioła ora]

\begin{tabular}{|c|c|c|c|c|c|c|c|c|c|c|c|c|}
\hline & \multicolumn{6}{|c|}{ Ágat APT } & \multicolumn{6}{|c|}{ Asgir Rogosi } \\
\hline \multirow{3}{*}{$\begin{array}{c}\text { Consuitraçion } \\
\text { de própoliss }\end{array}$} & \multicolumn{2}{|c|}{19 dia } & \multicolumn{2}{|c|}{$29 \mathrm{din}$} & \multicolumn{2}{|c|}{30 dia } & \multicolumn{2}{|c|}{19 dia } & \multicolumn{2}{|c|}{20 dia } & \multicolumn{2}{|c|}{30 dis } \\
\hline & $\mathrm{M}$ & W & $\mathrm{M}$ & w & $M$ & W & $\mathrm{M}$ & W & $M$ & W & $M$ & W \\
\hline & & & & & & & & & & & & \\
\hline $1.0 \%$ & 7 & - & $=$ & $\overline{=}$ & + & $+*$ & - & - & - & - & +- & th \\
\hline $0.5 \%$ & - & - & $=$ & + & t+ & +++ & - & + & - & $=$ & + & ++ \\
\hline $0.2 \%$ & + & + & + & + & $*+$ & +++ & - & +- & +- & + & + & t+ \\
\hline $0.1 \approx$ & + & +4 & - & ++ & ++ & +++ & +- & + & +- & + & ++ & ++4 \\
\hline $\mathrm{C} ; \mathrm{E}$ & t+t+ & +++ & +++ & +++ & +++ & +++ & ++ & +t & ++ & ++ & +++ & +++ \\
\hline C & $+\cdots$ & $++t$ & +++ & +++ & ++ & +++ & ++ & + & + & ++ & +++ & ++ \\
\hline
\end{tabular}

CiE - Controle en Etans?

CiE-Controle com Etanol C C - Controle

M-Maior Concentracio de Propolis. W-Menor soncentraço de Própolis

Variaçió do Número de Colonias; de - a ++1

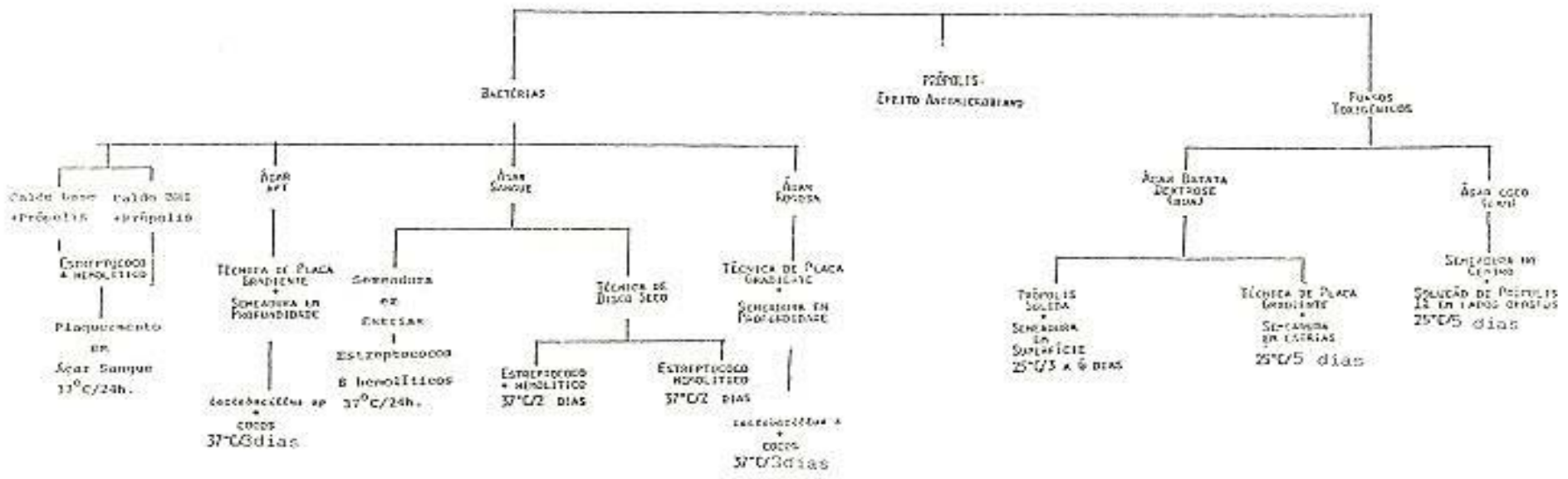


A tabela 3 analisa o efeito de própolis em estreptococos B -hemolíticos identificados como $S$. pyogenes ex-hemoliticos isolados da cavidade oral, pela técnica de semeadura em superficie.

Os estreptococos $\propto$-hemolíticos não foram inibidos pela própolis, enquanto que nos $\beta$-hemolíticos ocorreu halo näo hemolítico em torno de discos contendo a substância. Entretanto a inibição ocorreu somente a nível de produção de hemolisina, quando semeados em placas com a metade da superficie coberta com própolis. Estas linhagens retornaram a produzir hemolisina em ágar sangue sem própolis.

Tabela 3 - Ffeito da atividade antimierobiana de própolis no crescimento de estreptococoser e \& hemolíticos em inar sangue.

\begin{tabular}{|c|c|c|c|c|c|}
\hline \multirow{3}{*}{ MICRORGANISAO } & \multicolumn{5}{|c|}{ AGAR SANGUE } \\
\hline & \multicolumn{3}{|c|}{$\begin{array}{l}\text { Techife de Disco } \\
\text { Syco }\end{array}$} & \multicolumn{2}{|c|}{$\begin{array}{c}\text { Téeniea de Semseadura em } \\
\text { Estrias }\end{array}$} \\
\hline & $\mathrm{PB}^{2}$ & $\mathrm{PF}^{\mathrm{b}}$ & $\mathrm{ErOH}^{\mathrm{C}}$ & COM PROPDLIS & SEAM PROPOLLIS \\
\hline $\begin{array}{l}\text { Estreptocosos - crescimento } \\
\text { wf Hemolf́tic } \alpha \text { - Hemólise }\end{array}$ & $\dot{*}$ & $\dot{*}$ & $\stackrel{+}{+}$ & $N A^{d}$ & $\mathrm{NA}$ \\
\hline $\begin{array}{l}\text { Estreptococos - crescinento } \\
\text { A Henolíticos, Hembislixe } \\
\text { (Sir. pyogenes) }\end{array}$ & + & + & + & + & + \\
\hline 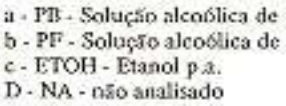 & es. & $\begin{array}{l}\text { bruts } \\
\text { fiftes }\end{array}$ & & & \\
\hline
\end{tabular}

A tabela 4 analisa o efeito da aeração em tubos contendo diferentes meios líquidos e confirmando o crescimento em ágar sangue. $O$ estreptococo $\beta$-hemolítico cresceu em todos os tubos sem própolis, porém na presença deste composto, nāo se desenvolveu em meios sem sangue na comparação de $\mathrm{BHI}+\mathrm{SG}$ e $\mathrm{CB}+0,7 \% \mathrm{NaCl}+\mathrm{SG}$ em cultura estacionária ou com agitação a $70 \mathrm{rpm}$, verificamos maior hemólise em cultura mantida sem agitaçăo.

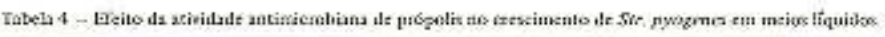

\begin{tabular}{|c|c|c|c|c|c|c|c|c|}
\hline \multirow{3}{*}{$\begin{array}{l}\text { MEIOS } \\
\text { DE } \\
\text { CULTURA }\end{array}$} & \multicolumn{4}{|c|}{ Dulters Escatiantifa } & \multicolumn{4}{|c|}{ Agritañ̄o a 70 RPSS } \\
\hline & \multicolumn{2}{|c|}{ Som Fropolis } & \multicolumn{2}{|c|}{ Campápals } & \multicolumn{2}{|c|}{ Sxan Fopolis } & \multicolumn{2}{|c|}{ Com Psógualí } \\
\hline & calda & Yho $x^{2} s^{2}$ & Calso & Flacans & Caldo & PLISA $\Omega S$. & Cldo & F1LANAS \\
\hline $3_{33} 0^{6}$ & & + & 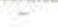 & $=$ & + & + & $=$ & \\
\hline $\mathrm{CB}^{\mathrm{C}}+0,4 \leq \mathrm{N} 2 \mathrm{Cl}$ & $+[\Leftrightarrow)^{d}$ & + & - & - & + & + & - & - \\
\hline $\mathrm{CB}+0,78 \mathrm{NaC1}$ & $+(<)$ & + & - & - & + & * & - & - \\
\hline $3 G^{t}+69$ II & $\mathrm{u}^{\mathrm{f}}$ & + & II & + & H & + & $\mathrm{H}(<)$ & + \\
\hline $\mathrm{sc}_{i}+\mathrm{CB}_{1}+0,4 \mathrm{~s}_{\mathrm{s}}$ & H & + & H & + & H & + & & + \\
\hline $8 \mathrm{G}+\mathrm{CB}-0,7 \mathrm{s \textrm {NaCl }}$ & H & + & $\mathrm{tt}$ & + & H & + & $\mathrm{H}(<)$ & +. \\
\hline
\end{tabular}

AS. 3 ger sungoe

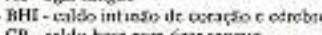

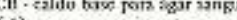

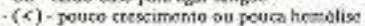

i. 1 - he heolise

\section{4 - DISCUSSÃO Ẹ CONCLUSÃO}

A melhor solubilização de própolis em solventes orgânicos moderadamente polares em relação a água, indica que esta substância contém componentes ativos de polaridade média.

Como foi demonstrado na tabela 1 , própolis não apresentou nenhuma inibiçāo sobre os fungos toxigênicos, tendo verificado que $P$. citrinum cresceu também sobre própolis "in natura" e quando cultivado em ágar-coco, tampouco ocorreu interferência na fluorescência devido a produção de micotoxinas.

Embora seja citado o efeito antifúngico de própolis em recomendaçōes oficiais, os nossos resultados evidenciaram nenhuma proteção contra fungos toxigênicos testados. Resultados semelhantes tem sido descritos por IALOMITEANU (1976) que constatou resistência de $A$. niger, $A$. flarus e Penicillum sp a 0,01 a $0,1 \mathrm{~g} \%$ de própolis, não ocorrendo o mesmo com Cladosporium sp.

Segundo DEREVICl (1976), própolis nāo inibiu o crescimento de $A$. niger $e$ Mucor mucedo inoculados em abelhas.

Quanto a microbiota oral (tabela2), própolis demonstrou açāo bacteriostática de pouca duraçăo, já que no decorrer da experiencia observou-se desenvolvimento gradativo das colônias. Aparentemente, o efeito inibitório inicial ocorreu exclusivamente devido a própolis e a adiçāo de quantidade equivalente de etanol nāo afetou o crescimento microbiano, devido à evaporaçāo do etanol durante o preparo do meio, mantido a $50^{\circ} \mathrm{C}$, descartando o efeito adicional do etanol descrito por GRECEANU \& ENCIU (1976). O efeito antibacteriano foi observado em várias espécies de Bacillus, $S$. atureus, Salmonella (PRADO FILHO \& AZEVEDO, 1962; AZEVEDO \& FLECHTMANN, 1963) e MERESTA \& MERESTA (1985) discute a aplicaçāo de própolis no tratamento de mastite bovina.

Analisando os estreptococos isolados da cavidade oral em ágar sangue, própolis inibiu apenas a produção de hemolisina por $S$. pyogenes (tabela 3 ) e nenhum efeito inibitório foi observado em estreptococos - hemolíticos tanto no crescimento como em hemólise indicando pouca interferência desta substância na microbiota oral, quando utilizada como antisséptico bucal.

Entretanto, devemos levar a essa consideração, propriedade altamente aderente de própolis em água que poderia alterar a absorção de nutrientes ou liberação de enzimas hidrolíticas no trato gastrointestinal.

Em função da composição do meio e aeração, própolis apresentou efeito bacteriostático, bactericida ou indiferente (tabclas 3 e 4) c este fato explicaria em parte, a observaçăo feita por KIVALKINA (1959 apud AZEVEDO \& FLECHTMANN, $1863 ; 1976$ ), onde foi observada diferença em açāo antibacteriana de própolis.

Assim, em caldo sem adição de sangue, própolis apresentou efeito bactericida, diferindo dos resultados da tabela 2 , onde observou efeito bacteriostático.

A maior hemólise observada em caldo com sangue em cultura estacionária (tabela 4) sugere que própolis bloqueia a produção, liberação e/ou atuação de estreptolisina $\mathrm{S}$, já que nāo ocorreu hemólise em placa de ágar snague contendo própolis (tabela 3 ).

A maior atividade hemolítica indiretamente significa maior crescimento e estaria de acordo com a literatura; os estreptococos apresentam metabolismo fermentativo e sendo catalase negativa (SCLEIFER, 1986), a baixa aeração favoreceria o crescimento devido a ausência de produtos reativos oriundos do metabolismo oxidativo (BEAMAN \& BEAMAN, 1984).

Por outro lado, segundo POPESCU et alii (1976), própolis contém transidrogenase anaeróbica que catalisa a trans. ferência de $\mathrm{H}^{+}$de NADPH para NAD ${ }^{*}$ (LEHNINGER, 1984), modificando os niveis energéticos celulares e consequentemente acclera a recuperação do paciente. Sendo as. sim, em baixa tensão de oxigênio, as hemácias deveriam estar mais protegidas; resultado inverso de nossos resultados (tabela 4).

Talvez, isto se deva ao fato de que, estando em cultura estacionária, a transidrogenase anaeróbica atuaria diminuindo niveis de NADPH, essencial para a estabilidade da membrana (LEHNINGER, 1984), facilitando a intercalaçäo da hemolisina na camada fosfolipídica, como foi demonstrado 
por IKIGAI \& NAKAE (1987 e b).

Esta situação provavelmente não ocorre in vivo, já que atividade biologica mantém reposição e nutrição constante das células.
Além disto, observamos que apesar da pequena açăo antimicrobiana de própolis, este efeito é complementado com atividades farmaco-dinâmicas e enzimáticas, resultando em propriedades terapẽuticas.

\begin{abstract}
Antimicrobial activity of propolis was studied in Streptococcus pyogenes, oral microflora and micotoxic fungi. CAM and PDA medium were used for fungal study and Rogosa, APT, BHI and blood for oral bacteria, using the combination of pourplate and szibaisky gradient plate technique. The toxic fungi were not inibited by propolis. Propolis showed bacteriostatic action on the oral microflora inoculated by pour plate technique in gradient plate, but the growth occured also with $1,0 \%$ propolis after 72 hours incubation. Concerning $S$. pyogenes, only haemolysin production was inhibite on blood agar, but bactericidal action was seen when inoculated in BHI + propolis broth. Effect of propolis on $S$. pyogenes depended on acration and nutrient composition, and probably both antimicrobial and pharmaco-dinamical propriety are important for the final effect on biologycal syst:m.
\end{abstract}

KEY WORDS: Propolis; Streptococcus pyogenes; Bactericidal; Bacteriostatic.

\title{
REFERENCIAS BIBLIOGRÁFICAS
}

1. AZEVEDO, J.L. \& FLECHTMANN, C.H.W. Ocorrência de substâncias antimicrobianas em produtos de alguns insetos sociais. Rev. Agricult, 38(3):129-36, Piracicaba, 1963.

2. BAUER, A.W.; KIRBY, W.M.M.; SHERRIS, J.G.; TURK, M. Antibiotic susceptibility by stancardized single disc method. Amer. J. Clin. Path., 45:493-96, 1986.

3. BEAMAN, L. \& BEAMAN, B. The role of oxygen and its derivatives in microbial pathogenisis and host defense. Ann. Rev. Microbiol. 38:24-48, 1984.

4. BRAUDE, A.I. Microbial susceptibility to drugs. In: Medical Microbiology and infections diseases. Philadelphia, Saunders Company, 1980. p. 210-34

5. DEREVICI, A. Contribuciones al estudo del propóleos :ln; SIMPOSIO INTERNACIONAL DE APITERAPIA, 2 Ntrevas investigaciones en la apiterapia. Bucarest, Ed. Apimondia, 1976. p. 237-56.

6. DIMITROV-MANGADIEV, N. Dados espectrales acerca de la composición mineral del propóleos del Bulgaria. In: SIMPÓSIO INTERNACIONAL DE APITERAPIA. 2. Nuevds investigaciones en la apiterapia, Bucarest, Ed. Apimondis, 1976. p. 162

7. GRECEANU, A. \& ENCIU, V. Algumas observaciones acerca del efecto antibiótico del propóleos, polen y miel. In: SIMPOSIO INTERNACIONAL DE APITERAPIA, 2. Nuevas investigaciones en la apiterapia. Bucarest, Ed. Apimondia, 1976. p. 182-5.

8. ialomiteanU, M. et alii. Perspectives del empleo terapeutico del propóleos in afecciones causadas por flagelados y leveduras. In: SIMPÓSIO INTERNACIONAL DE APITERAPIA, 2. Nuevas investigaciones en la apiterapia. Bucarest, Ed. Apimondia, 1976. p. 157-8.

9. IKIGAl, H. \& NAKAE, T. Assembiy of the -toxin-hexamer of $S$. aureus in the liposome membrane. J. Biol. Chem., $262(5): 2156-60,1987 a$.

10.

Interaction of the -toxin of $S$ aureus with the liposome membrane. J. Biol. Chem., $262(5): 2150-6,1987 \mathrm{~b}$
11. KIVALKINA, V.P. Balance y perspectivas de la investigacion del propóteos. In: STMPOSIO INTERNACIONAL DE APITERAPIA, 2. Nuevas investigaciontes en la apiterapia. Bucarest, Ed. Apimondis, 1976. p. 204.

12. LEHNINGER, A.I. Electron transport, oxydative phosphorylation, and regulation of ATP producion. In: $\quad$ Principles of biochemistry. New York, Worth Publi shers, 1982. pt. 2, chp. 17.

13. MERESTA, L. \& MERESTA, $\Upsilon$. An attempet to use the extract from propolis in the treatment of mastitis of cows. Med. Weter, 4l(8):489-92, 1985

14. MITSUHASFI, S. Resistance to antimicrobial drugs. In: BRAUDE, A.I. Medical microbiology and infections diseases. Fhiladelphia, Saunders Company, 1980. p. 247-55. New York, North Publ. Shers, 1982.

15. PALOS, E. et alii. Tecnologia de preparación del extracto blando de propóleos de uso farmaceutico in: SIMPOSIO INTERNACIONAL DE APITERAPIA, 2 NVuevas investigaciones en la apiterapia, Bucarest, Ed. Apimondia. 1976. p. $163-6$.

16. POPESCU, $V$, et alii. Determinacion de la actividad de las transhidrogenasas-anaerobicas y las sustancias generadoras de hidirógeno del propóleos. In: SIMPOSIO INTERNACIONAL DE APITERAPIA, 2. Nuevas investigaciones en la apiterapia. Bucarest, Ed. Apimondia, 1976. p. 209-13,

17. POPOVICI, N. \& OITA, N. Influencia de los extractos de propóleos en la mitosis en meristemas de Allium cepa $L$. In: SIMPOSIO INTERNACIONAL DE APITERAPIA. Nuevas investigaciones en la apiterapia. Bucarest, Ed. Apimondia, 1976. p. 373-5.

18. PRADO FILHO, L.G. et alii. Antimicrobianos em própolis de Apis mellifera L. Bol. Ind. Anim., 20:399-401, 1963.

19. SHLElFER, K.H. Gram-positive cocci. In: SNEAT, P.H.A.; MAIR, N.S.; SHARPE, M.E.; HOLT, J.G. Bergey's manual of systematic bacteriology. Baltimore, Williams \& Wilkins 1986. 2v. p. 999-1100.

20. TREVISAN, M.D.P. Própolis. Inf. Agropec., Belo Horizonte, $9(106): 50-2,1983$. 